\title{
Connecting Castings for Operation under Conditions of Cyclic Temperature Changes
}

\author{
Andrzej Drotlewa, Bogdan Piekarski ${ }^{*}{ }^{*}$ \\ aPrzedsiębiorstwo Usług Odlewniczych POLCAST Sp. J., Piastów 19 Ave., 70-310 Szczecin, Poland \\ ${ }^{b}$ West Pomeranian University of Technology in Szczecin, Department of Materials Technology, Piastów 19 Ave., 70-310 Szczecin, Poland \\ *e-mail: bogdan.piekarski@zut.edu.pl
}

(C) 2020 Authors. This is an open access publication, which can be used, distributed and reproduced in any medium according to the Creative Commons CC-BY 4.0 License requiring that the original work has been properly cited.

Received: 21 January 2020 /Accepted: 2 March 2020/ Published online: 30 March 2020

This article is published with open access at AGH University of Science and Technology Press

\begin{abstract}
The separable connections used in technological equipment of heat treatment furnaces (OTP) are described in this study. The equipment is used for the heat treatment of charges, i.e. for the thermal and thermo-chemical treatment of parts of machines and devices. OTP is used for the charge formation and its transport before, during and after heat treatment operations. Accessories of this type are usually compact structures composed of several or several dozen cast elements. The main components are grates and pillars, which form an outer contour of the OTP and also allow for the correct arrangement of heat-treated parts. To form a relatively rigid structure composed of the grates and pillars, it is necessary to join these components together. For this purpose, various types of separable connections are used, mainly of a cylindrical shape with threaded parts. The subject of this study is focused on the construction and operating conditions of typical OTP structures, as well as the methods of fastening the pillar in a grate, i.e. on the design of the bottom part of the pillar and the hole in the grate in which this pillar is embedded.
\end{abstract}

\section{Keywords:}

castings for heat treatment plants, grates, pillars, thermal fatigue

\section{INTRODUCTION}

Separable connections allow for multiple connecting and disconnecting of structural elements without damaging them. They are often used to join cooperating elements included in the technological equipment of heat treatment furnaces (OTP) [1-4].

The use of these connections in OTP facilitates:

- replacement of those components that wear out faster during operation,

- changes in the internal design when required by changes in the type of charge (shape and size of heat-treated parts).

Loose fit allows parts of OTP for relatively free thermal deformation within the range of operating temperatures. However, it should be noted that the operating conditions of some types of OTP may also require the use of inseparable connections. This applies especially to OTPs which are operated on fully automated production lines [2].

Accessories of this type are structures usually composed of several dozen cast elements differing in shape and size.
The main task of these structures is to form and handle the charge (heat-treated parts) during heat treatment operations. Castings are made from heat-resistant $\mathrm{Cr}-\mathrm{Ni}$ or $\mathrm{Ni}-\mathrm{Cr}$ steels, less often from nickel alloys. Thin walls of the same (as far as possible) thickness are a characteristic feature of individual OTP components (Figs. 1 and 2).

Typical examples of OTP commonly used in mass and large-lot heat treatment of small parts are the structures shown in Figures 1 and 2. They consist of a guide (load-bearing) grate, on which a structure composed of pillars and an intermediate grate (Fig. 1a), or pillars and crossbars (Figs. 1b and 2) rests. These accessories operate mainly in pusher furnaces, in which several units are simultaneously pushed in a row through the furnace working chamber. The number of levels in one OTP unit, where the heat-treated parts are laid or suspended, can be increased by means of the introduction of additional intermediate grates and spacers of the proper length (Fig. 1b).

The aim of this study was to describe separable connections on the example of a "hole-pillar" type connection joining the cooperating elements that form part of a typical OTP and to discuss the advantages and disadvantages of such designs. 
a)

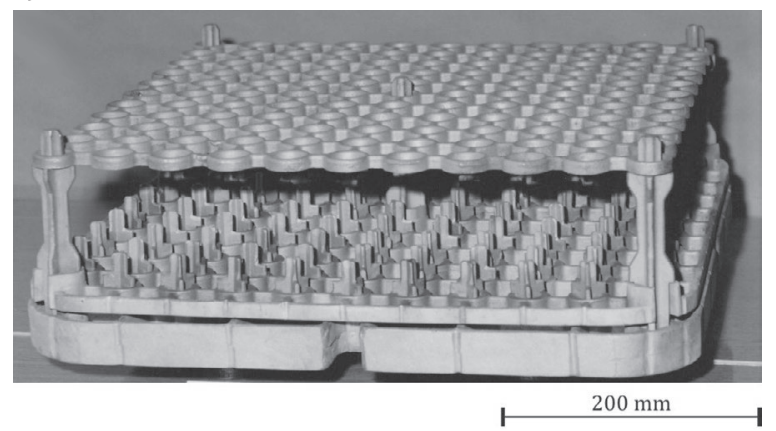

b)
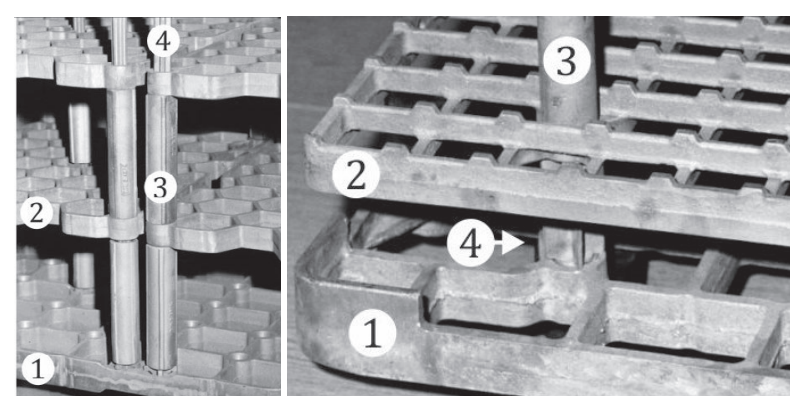

Fig. 1. Single-level OTP for operation in the pusher furnace consisting of a guide grate, intermediate grates and pillars (a) and fragments of two multi-level OTPs for operation in the chamber furnace, the design of which also required the use of spacers (b): 1 - gude grate, 2 - intermediate grate, 3 - spacer, 4 - pillar; according to [2]

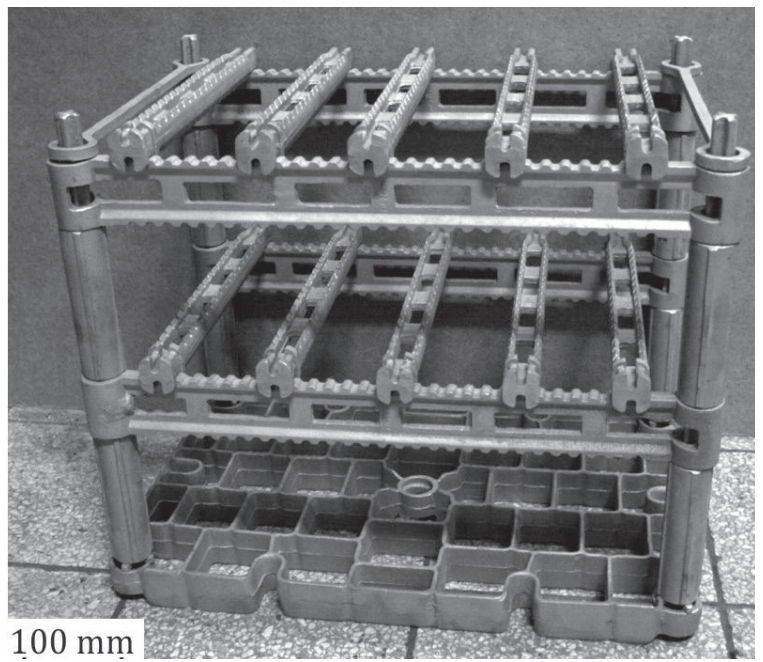

Fig. 2. Two-level OTP for operation in the pusher furnace consisting of a guide grate, pillars, spacers and crossbars [2]

\section{OTP OPERATION}

The initially satisfactory performance characteristics of OTP undergo degradation during operation due to the processes of aging, high temperature corrosion and thermal fatigue. As a result of the impact of these factors, deformation and/or cracking of the OTP walls takes place, combined with the detachment of fragments of these walls. At the same time, it should be assumed that resistance to thermal fatigue is the main factor responsible for the durability of OTP $[2,5-6]$.
Changes in the dimensions of OTP components during heating/cooling of the charge subjected to heat treatment or thermo-chemical treatment are of a complex nature resulting from the synergy of numerous factors, such as maximum operating temperature, type of treatment, conditions of the charge cooling and its mass, the shape and dimensions of heat-treated parts, or the degree of the OTP structure complexity (see Figs. 1 and 2). The simplest design of the equipment is shown in Figure 3a. Connecting the grates with pillars reduces the mutual risk of thermal deformations occurring in parts of the guide grate and intermediate grate. In each cycle of the heat treatment, in the intermediate grate with the walls usually thinner than the walls of the guide grate, the process of heating and cooling proceeds at a much higher speed. Therefore, pillars connecting the grates are bent outwards during heating of the charge (Fig. 3b) and inwards during cooling (Fig. 3c). The cyclic nature of these processes means that in the OTP whose design is based on a guide grate and intermediate grates (Fig. 3a), mainly pillars (Fig. 4) and corners of the grates will be damaged [2].

a)

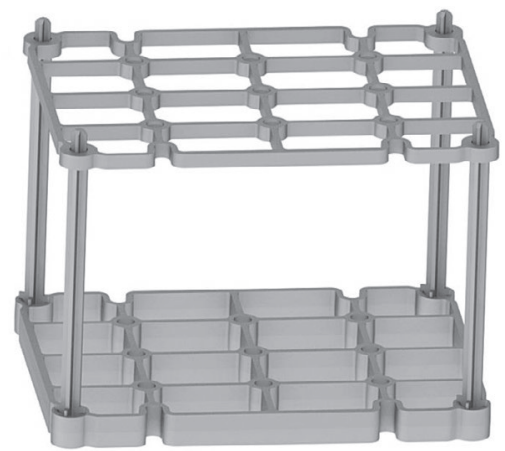

b)

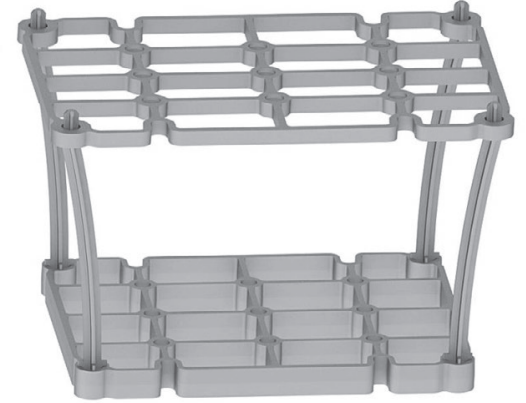

c)

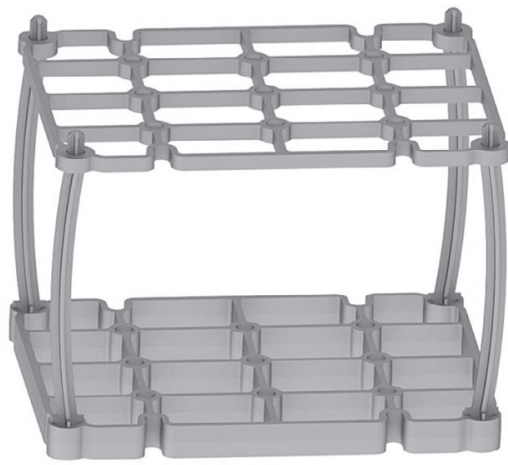

Fig. 3. Diagram of changes in the shape of OTP during operation: a) condition before operation; b) high-speed heating; c) fast cooling; according to [7] 
Industrial practice also shows that in this type of OTP, pillars are the components which are exposed to the highest wear rate [2]. Their decommissioning occurs primarily as a result of the through-cracking (breaking off) of the lower part of the pillar mounted in a hole made in the guide grate (Fig. 4).

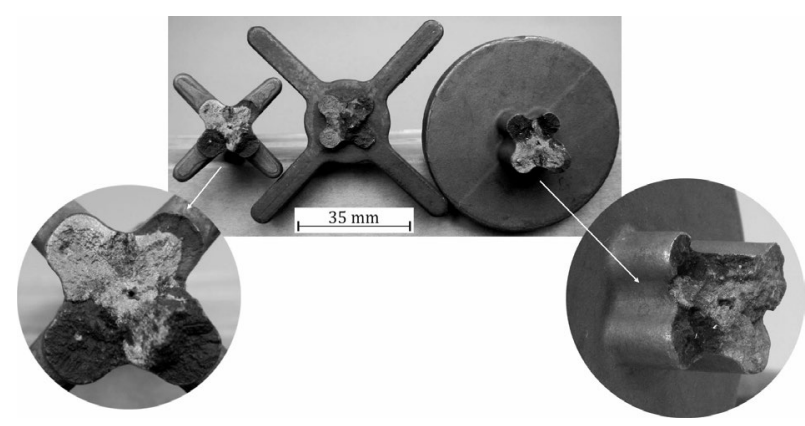

Fig. 4. Fractures in the lower part of the pillar formed as a result of the breaking off of its fragment during operation

\section{SEPARABLE CONNECTIONS OF THE “HOLE-PILLAR" TYPE}

Pillars serving as vertical supports in the OTP structure are the main component which connects the guide grate and intermediate grates. Traditionally designed (Figs. 5 and 6), they have a fixed, cruciform cross-section that provides them with the expected stiffness, a length from 200 to even $3000 \mathrm{~mm}$, and cross-sectional dimensions described by a circle with a diameter of 15 to $50 \mathrm{~mm}$.

The pillars consist of three main parts (Figs. 1-3):

- shaft - a long part whose basic task is to enable the installation of other transverse elements of the OTP structure in the guide grate. The length of the shaft depends on the shape and dimensions of heat-treated parts and on their arrangement; it is also limited by the height of the furnace working chamber,

- support - forming the abutment surface necessary for mounting the pillar. As a rule, it has a 4-arm or round shape (Fig. 4). The support has a thickness of the shaft wall and a diameter corresponding to the outer diameter of the hole in which the pillar is mounted,

- base - a short part, used to fix the pillar in the guide grate. Its length is usually equal to the height of the guide grate.

The thin-walled structure of the OTP cast components results in their simultaneous solidification. Therefore, it is inevitable that larger volumes of the cast material separated by the thin walls will form areas with an increased concentration of internal shrinkage defects, such as shrinkage porosities and cavities. a)

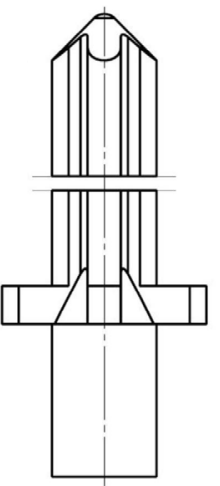

b)

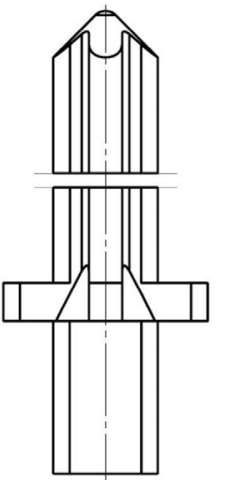

c)

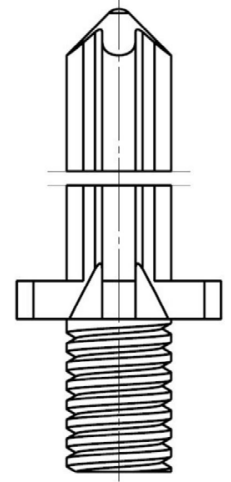

d)

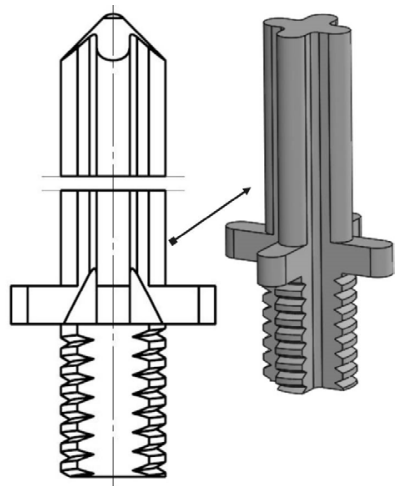

Fig. 5. The design of the pillar with a cylindrical base (a); cylindrical-oval base (b) and additionally threaded base (c, d)

a)

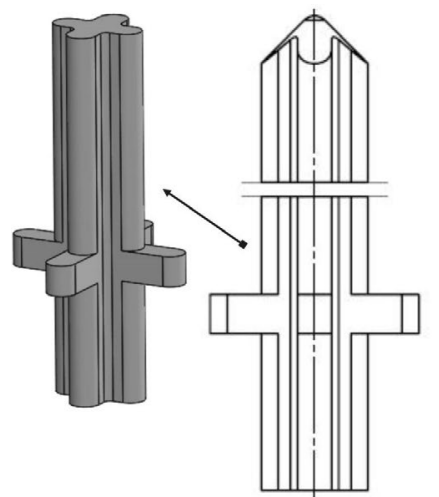

b)

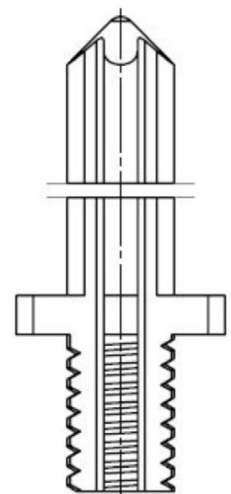

c)

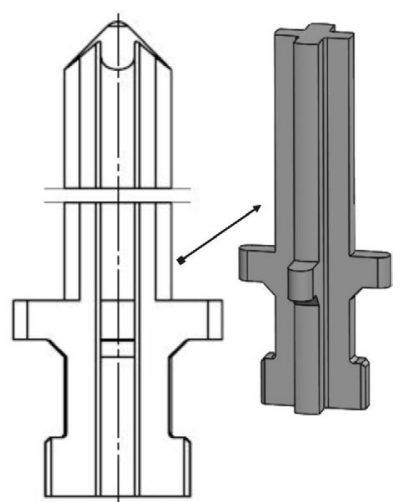

Fig. 6. The design of the pillar with a cruciform cross-section base. Base: a) standard; b) with extra threads; c) bayonet-like shaped 
In a pillar, such a massive area (local thermal node) that will solidify longer than the neighboring areas is the common area of the shaft and support (see Fig. 4). In pillars of the design shown in Figure 5, the occurrence of shrinkage defects can be significantly minimized by feeding an extra volume of liquid metal to this area through the base of the pillar during the solidification period. The design of a gating system with a lateral feeder (riser) ensuring liquid metal flow to the mould cavity from the side of the pillar base seems to be a solution whose effectiveness is guaranteed by a sufficiently large cross-section of the pillar base. In other pillars (Fig. 6), this solution will not be effective due to the small cross-section of the pillar base.

In all pillars (Figs. 5 and 6), the casting of the base does not require the use of cores. If the roughness of the raw surface is $R_{a}<40 \mu \mathrm{m}$, the pillars can be easily and efficiently fixed in the holes of the guide grate without the need for mechanical treatment. On the other hand, it is necessary to ensure that both the base surface and other surfaces of these castings are free from defects typically occurring in the as-cast condition, such as microfolds or micro-cold shuts. Defects of this type can facilitate the nucleation and development of cracks and accelerate in this way the destruction of pillars under the conditions of thermal fatigue.

The shape of the holes made in the guide grate for fixing the pillars is shown in Figure 7.

In the design of the holes, there are also areas (local thermal nodes) with increased concentrations of internal defects. These are the places in the grate walls that are directly adjacent to the holes. Their massiveness can be reduced by properly selected radii [1-3] and recesses made in the material surrounding the hole (Fig. 7a).

Generally, the outer contour of the grate undergoes faster degradation during operation than the inner part because it is heated/cooled at a higher speed compared to the middle part where the charge is resting. At the same time, the places in the walls adjacent to the holes are the source of the largest number of cracks [2]. This degradation process can be slowed down by the use of reinforcing ribs (Fig. 8), similar to shrinkage ribs used in casting. They facilitate heat dissipation from the wall sections with the largest thickness but also make the grate structure more rigid. Therefore, the decision to introduce them should be carefully considered, taking into account the variable thermal loads to the effect of which the OTP is subjected during its operation. a)
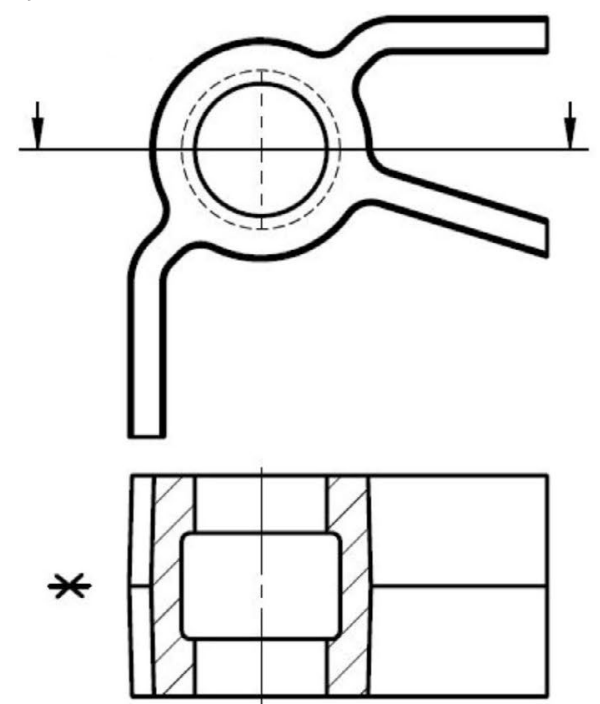

b)
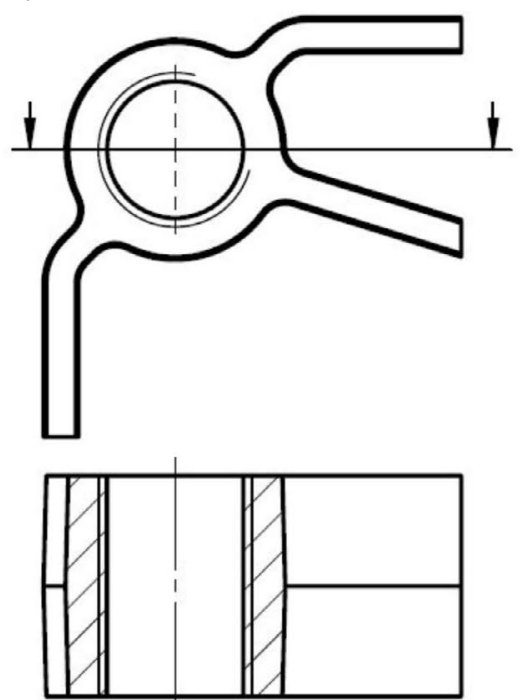

c)
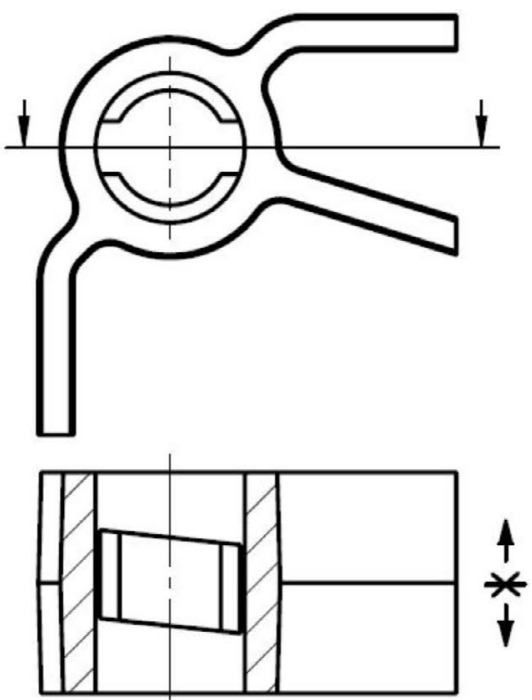

Fig. 7. The design of the holes in the guide grate for fixing the pillars shown in Figures: a) 5a-b and 6a; b) 5c-d and 6b; c) 6c

a)

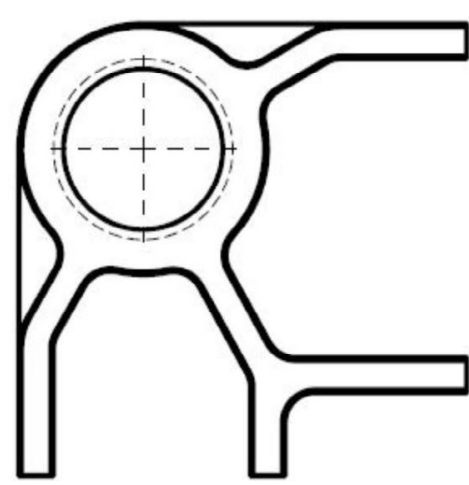

b)

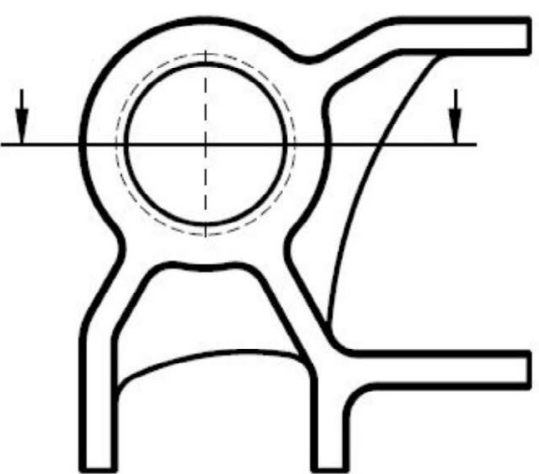

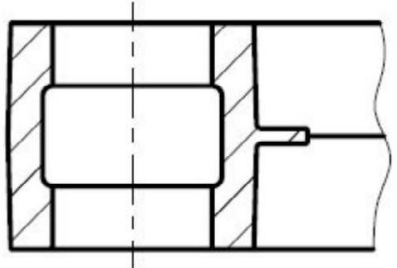

Fig. 8. Reinforcing ribs in the corners of the grate with holes for fixing the pillars: a) external; b) internal 
The thickness of the ribs $g$ is calculated following the design recommendations for shrinkage ribs $[8,9]$, based on the casting wall thickness $d: g=(0.2-0.3) d$, where the minimum value of $g$ should be $\geq 2.5 \mathrm{~mm}$.

Temperature gradients in more massive areas of the OTP can also be reduced by recesses made in the material adjacent to the holes (Fig. 9). They facilitate the circulation of the cooling liquid (coolant) around the "hole-pillar" surface, thus allowing for more intense cooling.

The first two solutions require additional comments and explanations (Fig. 9a and b). In the inner holes, threaded ribs can also be used (Fig. 9a). In the holes with recesses on the front surfaces (Fig. 9b), pillars with round support should be mounted (see Fig. 4).

Apart from the typical, previously described designs, separable connections of the "hole-pillar" type can also have another non-standard form (see Fig. 10). In the method of fixing intermediate grates in OTP shown in the drawing, it is not only important that this method solves the problem of positioning the grates in a completely different manner, but it is also important that the consequence of this change will be an OTP with a lighter weight due to the elimination of spacers and metal volumes in those areas that would be considered very massive (increasing instantaneous temperature gradients), if a traditional solution were used. As a result of this modification, one can expect both a reduction in the OTP operating cost and an increase in its durability.

Multi-level OTP designs consist of the corresponding number of intermediate grates / crossbars and spacers of the proper length (Figs. 1b, 2 and 10). Solutions are also used in which the height of the first and, at the same time, lowest level can be set by a pillar with two-step cross-section (see Fig. 1b, right). In the OTP shown in Figure 10, the design problem has been solved in a different way. The unit can have maximum 4 levels. Their height is determined by proper spacing of the horizontal ribs along the pillar height (see Fig. 10), where a rib is placed on the pillar at the next level but rotated in a horizontal plane by $90^{\circ}$ in relation to the previous one. a)
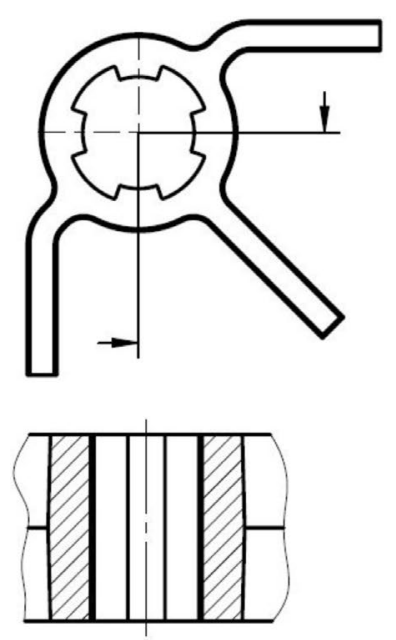

b)

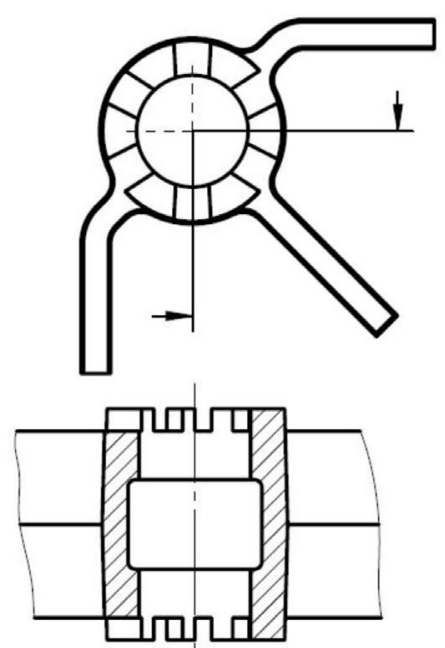

c)
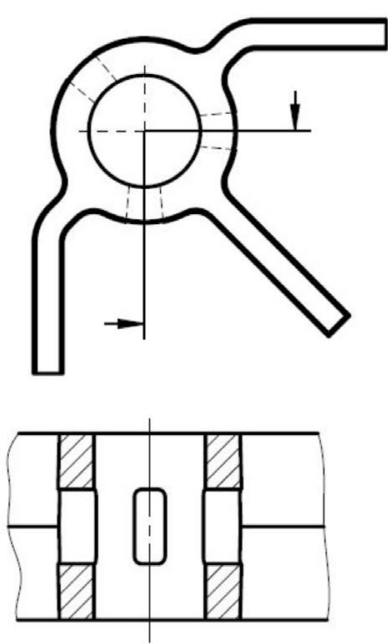

Fig. 9. The solutions used in the design of grate holes for fixing the pillars: a) internally ribbed hole; b) hole with recesses on the front surfaces; c) hole with recesses on the side surface

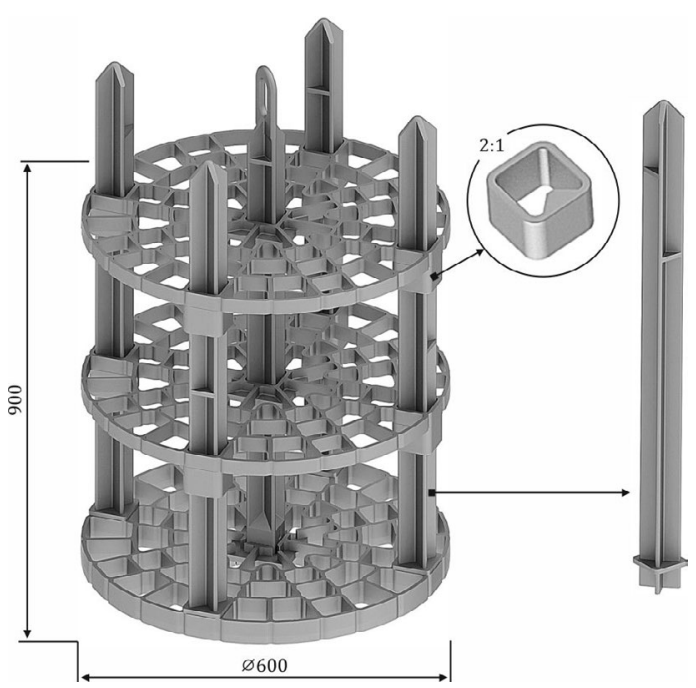

Fig. 10. OTP for operation in the pit furnace with pillars and holes for fixing these pillars of a non-typical design 
A retainer rests on the rib and supports the intermediate grate. In this OTP, the idea of using traditional (round) holes for fastening pillars was abandoned. They were replaced with square holes blocking the pillars rotating movement and facilitating the OTP assembly.

\section{FINAL REMARKS}

To have an unrestrained possibility of introducing changes to the dimensions of individual OTP components, it is necessary to understand the processes which a structure of this type will be exposed to during operation. Generally speaking, referring to earlier comments on the design of separable "hole-pillar" type connections, the following should be stated:

1. Use connections where the coolant can penetrate relatively easily between the pillar shaft and the mounting hole. This will be beneficial for OTP durability as it will reduce the stress concentration in these areas of the structure. This condition is better met by pillars with a cruciform cross-sectional base than those with a cylindrical oval base.

2. Avoid rigid connections. These are primarily the threaded connections, which in practice prevent individual OTP elements from relatively free changes of dimensions in the variable field of temperatures. Regardless of this fact, their use in large and high OTPs is usually necessary. When OTP is moving inside the furnace chamber or outside the furnace, there is always a risk that the charge will get "loose" and the heat-treated parts will fall off the hooks.
3. When designing OTP elements, all solutions that allow the reduction in the volume of local thermal nodes should be used, remembering that the nodes:

- give rise to the concentration of thermal stresses in these areas during casting manufacture and later operation,

- give rise to the concentration of internal shrinkage defects, which are convenient places for later nucleation and development of cracks.

\section{REFERENCES}

[1] Steinkusch W. (1985). Verbesserte Werkstoff und Konstruktionen verringern Betriebskosten bei der Wärmebehandlung. Fachberichte Hütten. Metall. 23, 746-749.

[2] Piekarski B. (2012). Odlewy ze stopów żarowytrzymałych w piecach do obróbki cieplnej. Szczecin: Wydawnictwo Uczelniane ZUT w Szczecinie.

[3] Folders: Lohmann, Cronite, Pose-Marre, Technoalloy, MANOIR PETRO-CHEM, AFE Technologies, NCK.

[4] Drotlew A., Piekarski B. \& Słowik J. (2017). The design of cast technological equipment for heat treatment furnaces. Archives of Foundry Engineering, 17(3), 31-36.

[5] Bajwoluk A. \& Gutowski P. (2017). The Effect of Cooling Agent on Stress and Deformation of Charge-loaded Cast Pallets. Archives of Foundry Engineering, 17(4), 13-18.

[6] Bajwoluk A. \& Gutowski P. (2019). Stress and crack propagation in the surface layer of carburized stable austenitic alloys during cooling. Materials at High Temperatures, 36(1), 9-18.

[7] Piekarski B. (2010). Damage of heat-resistant castings in a carburizing furnace. Engineering Failure Analysis, 17(1), 143-149.

[8] Kniaginin G. (1977). Metalurgia i odlewnictwo staliwa. Katowice: Wydawnictwo „Śląsk”.

[9] Telejko I. (1986). Naprężenia i pęknięcia $w$ odlewach staliwnych. In: Zarys metalurgii i odlewnictwa staliwa: praca zbiorowa. Cz. 2, Odlewnictwo, Ed. A. Staronka, Skrypty Uczelniane Akademia Górniczo-Hutnicza nr 1023, 180-224. 